ISBN 978-981-11-0008-6

Proceedings of 2016 6th International Workshop on Computer Science and Engineering

(WCSE 2016)

Tokyo, Japan, 17-19 June, 2016, pp. 734-737

\title{
The Kamchatka Volcano Video Monitoring System
}

\author{
Aleksei Sorokin ${ }^{1}$, Sergei Korolev ${ }^{1+}$, Iraida Romanova ${ }^{2}$, Olga Girina ${ }^{2}$ and Igor Urmanov ${ }^{1}$ \\ ${ }^{1}$ Computing Center, Far Eastern Branch, Russian Academy of Sciences, Khabarovsk, Russia \\ ${ }^{2}$ Institute of Volcanology and Seismology, Far Eastern Branch, Russian Academy of Sciences, \\ Petropavlovsk-Kamchatsky, Russia
}

\begin{abstract}
The Kamchatka volcano video monitoring system, its operational principles and the developed algorithms for image processing are described. The created software provides the solution of a set of problems related to centralized imagery management, searching for images in the database and, also, their transmittance to the external specialized information systems for further joint analysis in combination with the data of other observations of Kamchatka volcanoes.
\end{abstract}

Keywords: volcano, image, information system, algorithm, contour, database, web-service.

\section{Introduction}

Video observation is the type of instrumental observations used to monitor and visually estimate the state of various objects, including natural objects such as volcanoes. Using the video camera allows remote and permanent observations of an object and, also, analysing changes in its state, and/or an occurring eruption based on a set of images.

Owing to high activity of Kamchatka volcanoes and the necessity to conduct their studies and operative monitoring, the work on implementing the multifunctional video observation system is carried out by the joint efforts of Kamchatkan Volcanic Eruption Response Team (KVERT) of the Institute of Volcanology and Seismology, the Far Eastern Branch, Russian Academy of Sciences, (IVS FEB RAS) [1], and the Computing Center, Far Eastern Branch, Russian Academy of Sciences, (CC FEB RAS). The system includes several components providing the solution of a range of problems related to inventory of objects and observation facilities, video camera managing, data archiving and image processing. As a result of the subsystem operation during five years, an array of unique images of a total number of about five million has been accumulated.

The created and augment structured image archives are used as one of the data sources in a comprehensive information system VolSatView for monitoring Kamchatka volcanoes [2]. Based on the joint analysis of data obtained using various types of observations which involve video observations, remote sensing data, computer modelling, etc., the system allows state estimation of natural objects.

The goal of the paper is to give a brief description of the created information video observation system and its operational principles.

\section{Problem Setting}

In order to visually monitor the state of Sheveluch, Klyuchevskoy, Avachinsky and Gorely volcanoes, six video cameras have been installed since December, 2009, by the researchers of IVS FEB RAS and CC FEB RAS in the settlement of Klyuchi and the city of Petropavlovsk-Kamchatsky. The facilities were

\footnotetext{
${ }^{+}$Corresponding author. Tel.: + 79141965534; fax: +7(4212)227267.
}

E-mail address: serejk@febras.net. 
plugged in to the telecommunication channels of the Regional computer network of FEB RAS [3], and the main archive was allocated in the Data Center of FEB RAS (Khabarovsk) (Fig. 1).

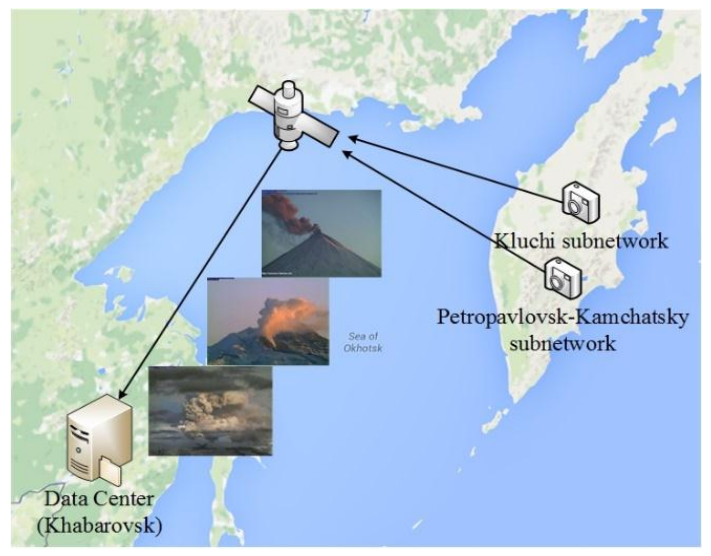

Fig. 1: Video observation network of FEB RAS.

The study and monitoring of volcanic activity in Kamchatka using video cameras has specific features that affect the implementation of video observation system operation. They are as follows:

- a remote distance of the majority of natural objects from the settlement and the absence of groundbased and high speed communication channels prevent real-time video data remote operation;

- the functional capabilities of the used facilities have constraints;

- a large number of the obtained images are not informative due to features of the used facilities, the install locations and weather conditions.

Taking into consideration the aforementioned constraints, the following key system requirements have been determined.

1. The time interval between periodic image fetching from video camera should be defined based on the volcano activity. Since the volcano monitoring is linked to the problems concerned with aviation safety in the region, the Aviation color code assigned to the volcano by KVERT is assumed to be used as the formalized indicator of the volcano state.

2. After the image has been captured by video camera and further archived, the population of appropriate image metadata (the observation object, fetch time, etc.) is necessary.

3. The filtering algorithms should be implemented for volcano imaging, which allow a preliminary qualitative estimation of the image obtained.

\section{Volcano video monitoring system}

\subsection{System architecture}

The problems set have been solved by creating an appropriate software and its plugging-in, as a specialized block, to the "Signal" platform [4], used to provide the operation of the instrumental observation network of FEB RAS [5-6] and to manage its resources (Fig. 2).

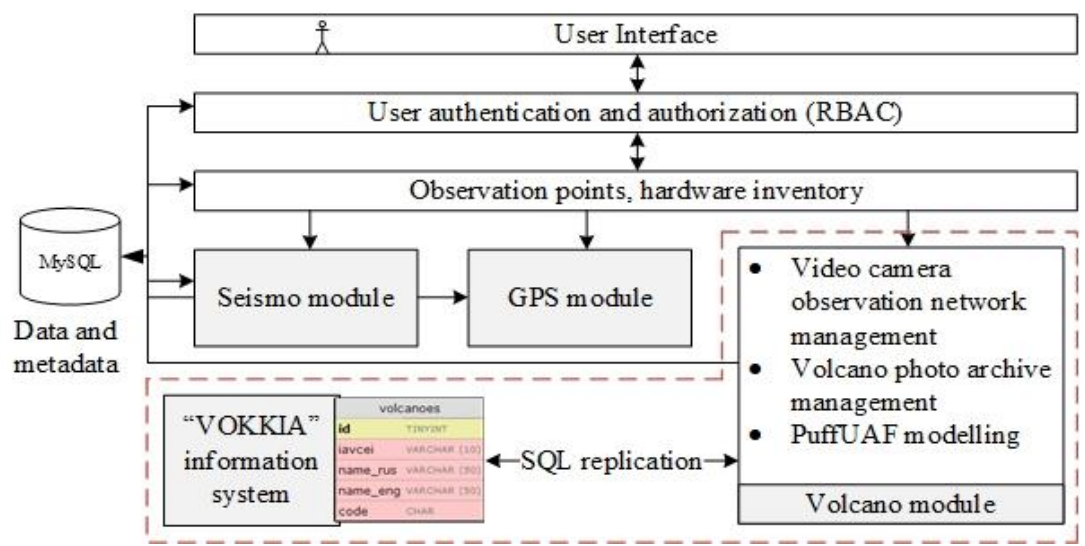

Fig. 2: General "Signal” architecture with volcano video module integrated. 
The proposed implementation of the system has allowed us to comprehensively solve the issues linked to the organization of the video observation network operation, including:

- issuing passports for the investigated objects and observation facilities;

- providing centralized data storage for all types of observations and works;

- multi-user work mode, which controls user rights for the access to data archives, launching the services for data processing, execution of operations for object registration, etc.;

- remote searching for and receiving images from the system archive via the Web-service.

In addition, the data interaction between Volcanoes of the Kurile-Kamchatka Island Arc (VOKKIA) information system [7] and AIS "Signal" made it possible to link the aviation color code for the volcano to the time interval between periodic image fetching from video camera, and, also, to update metadata on the investigated natural objects based on the reference data and Volcano Observatory Notice for Aviation (VONA) that contain up-to-date information on Kamchatka eruptions.

All system operations and the access to the accumulated data archives are executed via the user interface, which is implemented as the web-browser application (Fig. 3).

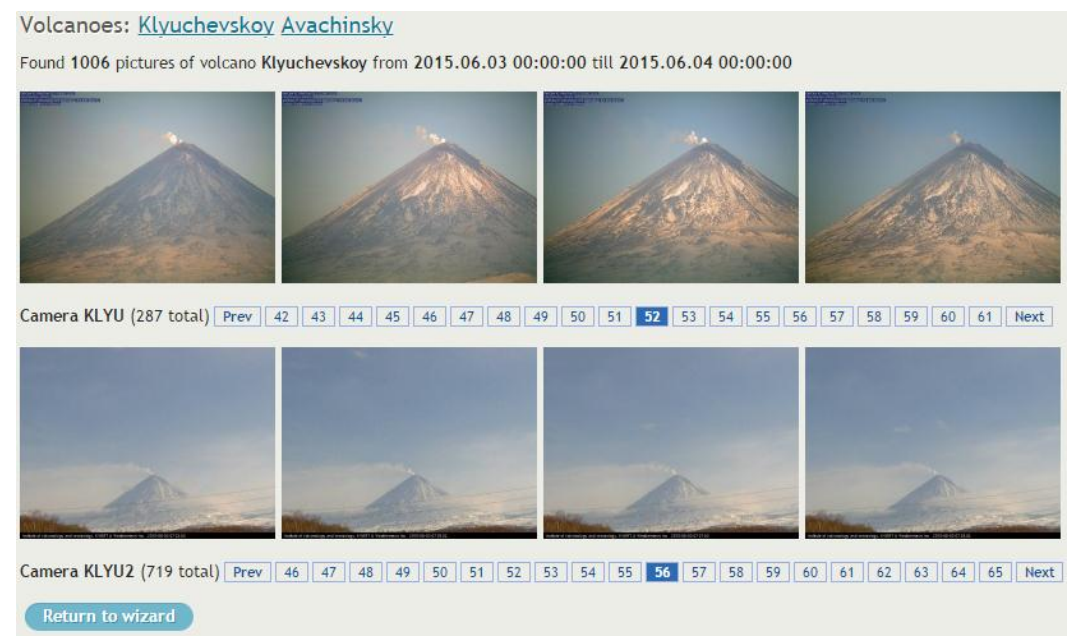

Fig. 3: "Signal" video archive browsing page.

The software components of the interface are created within the framework of the "Model-ViewController" (MVC) concept [8]. This approach allows the functional extension at each of the system levels, provides the interaction with different data sources, storage systems, and, also, enables the creation of specialized modules for data processing. The Yii framework is used for MVC software implementation.

\subsection{The image processing}

The created software allows us to automatically obtain images using video cameras installed in close proximity to Kamchatka volcanoes. However, the possibility of using cameras causes a set of problems associated with insufficient quality and informativity of the captured images that are affected by different factors. In order to unequivocally identify and filter the images that are neither qualitative nor informative, we are developing the algorithms and methods for evaluation of volcano images and their implementation on the software basis.

To date, testing of the program for image evaluation is performed, based on the comparison of the volcano contours, given as the parametric models [9]. This method provides image filtering on the basis of the contour visibility of the observation object. The experiments show that the determined visibility estimations are adequate in the majority of cases.

\section{Conclusion}

The created video observation system for Kamchatka volcanoes allows the solution of the necessary set of problems that are related to the centralized imagery management, searching for the images in the database, and, also, their transmittance to the external specialized information systems for further joint analysis in combination with the data obtained using other types of observations for Kamchatka volcanoes. 
The further development of the system is linked to the studies and creation of the algorithms for the analysis of volcano images. Their software implementation and the application for captured image preprocessing will increase the informativity of these data types and, as a result, the efficiency of estimation of the volcano state.

\section{Acknowledgements}

The studies were supported by the Program of Fundamental Studies of the Far Eastern Branch of the RAS "The Far East" (No. 15-I-4-071, 15-I-4-072) and by the Russian Foundation for Basic Research (No. 16-07-00156, 16-37-00026 mol_a).

The created volcano imagery archives and operations tools are used to implement the Project of the Russian Science Foundation No. 16-17-00042.

\section{References}

[1] O.A. Girina, E.I. Gordeev. KVERT Project - aviation volcanic hazard mitigation during explosive eruptions of Kamchatka and North Kuril volcanoes. Bulletin of the Far Eastern Branch of the RAS. 2007, 2: 100-109.

[2] V.Yu. Efremov, O.A. Girina, L.S. Kramareva, et al. Creation of the information service "Remote Monitoring of Active Volcanoes of Kamchatka and the Kuril Islands". Modern problems of remote sensing of the Earth from Outer Space. 2012, 9 (5): 155-170.

[3] A.I. Khanchuk, A.A. Sorokin, S.I. Smagin, et al. Development of the information-telecommunication systems in FEB RAS. Information technologies and computation systems. 2013, 4: 45-57.

[4] A.A. Sorokin, S.P. Korolev, I.P. Urmanov, et al. Software Platform for Observation Networks Instrumental Data Far Eastern Branch of the Russian Academy of Sciences. Proc. of International Conference on Computer Science and Environmental Engineering (CSEE 2015). Beijing. 2015, pp. 589-594.

[5] A.I. Khanchuk, A.V. Konovalov, A.A. Sorokin, et al. Instrumental and IT-technological provision of seismological observations in the Russian Far East. Bulletin of the Far Eastern Branch of the RAS. 2011, 157 (3): $127-137$.

[6] N.V. Shestakov, H. Takahashi, M. Ohzono, et al. Analysis of the far-field crustal displacements caused by the 2011 Great Tohoku earthquake inferred from continuous GPS observations. Tectonophysics. 2012, 524-525C: $76-$ 86.

[7] I.M. Romanova, O.A. Girina, A.P. Maksimov, I.V. Melekestsev. Creation of the complex information web-system "Volcanoes of the Kuril-Kamchatka Island Arc" (VOKKIA). Information science and managing systems. 2012, 3 (33): 179-187.

[8] M. Fowler. Patterns of Enterprise Application Architecture. Addison-Wesley Professional. 2002: 560 p.

[9] J. Canny. A computational approach to edge detection. IEEE Transactions on Pattern Analysis and Machine Intelligence. 1986, 8 (6): 679-698. 